\title{
High-mobility group box 1 protein, angiotensins, ACE2, and target organ damage
}

\author{
Friedrich C. Luft $^{1}$
}

Published online: 11 December 2015

(C) Springer-Verlag Berlin Heidelberg 2015

High-mobility group box 1 (HMGB1) protein is an important chromatin protein. In the nucleus, HMGB1 interacts with nucleosomes, transcription factors, and histones. The nuclear protein organizes the DNA and regulates transcription [1]. After binding to DNA, HMGB1 bends DNA, thereby facilitating the binding of other proteins. HMGB1 supports transcription of many genes in interactions with numerous transcription factors. HMGB1 also interacts with nucleosomes to loosen packed DNA and remodel the chromatin. Contact with core histones changes the structure of nucleosomes. The presence of HMGB1 in the nucleus depends on posttranslational modifications. When the protein is not acetylated, it remains within the nucleus; however, hyper acetylation on lysine residues causes HMGB1 to translocate into the cytosol [2]. Here, HMGB1 assumes quite different roles. Immune cells can secrete the protein. For instance, dendritic cells, macrophages, and monocytes secrete HMGB1 in response to cytokines to mediate inflammation. The mechanism of inflammation and damage is HMGB1 binding to receptor for advanced glycation end products (RAGE), Toll-like receptor 2 (TLR2), and TLR4 to mediate nuclear factor kappaB (NF-KB) activation [3]. This state-of-affairs positions HMGB1 at the intersection of sterile and infectious inflammatory responses $[4,5]$. The multifaceted activities of HMGB1 (Fig. 1) have been reviewed (5).

Friedrich C. Luft

luft@charite.de

1 Experimental and Clinical Research Center, Charité Medical Faculty and the Max Delbrück Center for Molecular Medicine,

Lindenbergerweg 80, 13125 Berlin, Germany
Evidence has been presented that angiotensinconverting enzyme (ACE) inhibitors and angiotensin receptor blockers (ARB) can reduce secretion of HMGB1 [6, 7]. This observation would be consistent with possible interactions between HMGB1 and the renin-angiotensin system. The angiotensin-converting enzyme (ACE) is a matrix metalloproteinase cleaving decapeptide angiotensin (Ang) I to the octapeptide Ang II. ACE, and its orthologs possess 2 peptidase M2 domains. ACE2, discovered more recently but probably a teleological older enzyme, and its orthologs possess a single peptidase M2 domain. Ang I and II can be cleaved by ACE2 into nonapeptides (Ang1-9) and septapeptides (Ang1-7), respectively. The ACE2 protein also serves as a receptor for corona viruses. The ACE metalloproteinases have been around on the planet for a long time. Similar sequences are found in flies and even in bacteria, while renin first enters the scene at the bony-fish level [8].

The generation of Ang1-7 by ACE2 is said to have a vascular protective function. Nevertheless, ACE2 targeting in mice resulted in mixed messages. There have been at least three lines of ACE2 knockout mice reported by various investigators [9]. Interestingly, there are significant differences in the phenotypes of these distinct lines, especially with regard to their cardiovascular physiology. ACE2 appears to have only modest effects on baseline cardiovascular functions and blood pressure control. These effects can be substantially modulated by genetic and, perhaps through environmental factors. In contrast, the activity of ACE2 may have more profound effects on susceptibility to pathological states, such as hypertension and cardiac hypertrophy.

In this issue of $\mathrm{J}$ Mol Med, Qi et al. [10] studied mice harboring a FLAG-tagged mouse ACE2 gene 


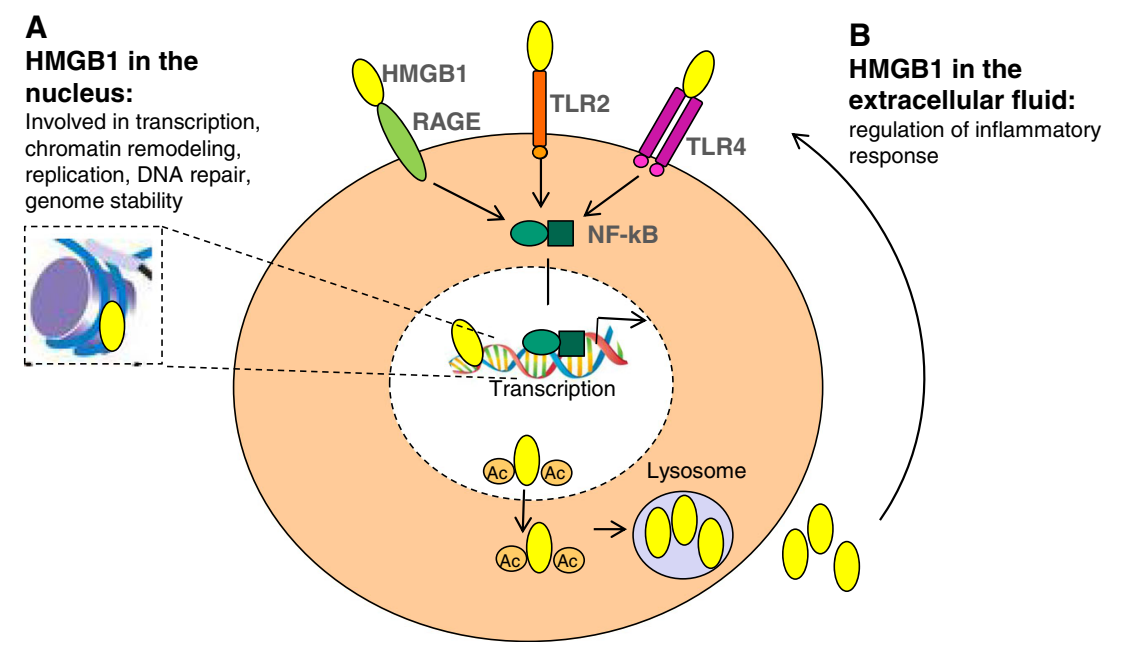

Fig. 1 The diverse activities of High-mobility group box 1 (HMGB1) protein. a HMGB1 in the nucleus is found associated with nucleosomes [5]. Here, HMGB1 is important for spatial segregation and controlling transcription of DNA, and for interacting with the nuclear matrix. $\mathbf{b}$ In the extracellular fluid (following secretion from macrophages/monocytes after activation by endotoxin, tumor necrosis factor (TNF), interleukin-1
(IL-1), and interferon-gamma (IFN-gamma) or passive release by necrosis), HMGB1 is involved in the regulation of the inflammatory response. HMGB1 signals through receptor for advanced glycation end products (RAGE), Toll-like receptor 2 (TLR2), and TLR4, nuclear factor kappaB (NF-kappaB) and the mitogen-activated protein kinase $\mathrm{p} 38$ (knock-in) under the control of an endogenous promoter. These mice exhibited a 50 -fold increase in ACE2 expression in the heart. The mice then underwent occlusion of the left anterior descending coronary artery producing myocardial infarction. Nontransgenic control mice were subjected to the same procedure. Echocardiography and direct measurements of cardiac performance were performed. While ejection fraction plummeted by $59 \%$ in normal mice, ACE2 overexpressing mice exhibited only a $21 \%$ reduction in ejection fraction. The infarct size was also reduced by $50 \%$. The investigators then measured protein levels of ACE, ACE2, angiotensin II type-1 receptor (AT1R), angiotensin II type-2 receptor (AT2R), and the Mas receptor in the free wall of the left ventricles collected from normal shams, normal mice with infarction, and the corresponding ACE2 transgenic sham and infarcted mice. The ACE2 transgenic mice had the expected marked increase in ACE2 protein. The ACE protein increased in infarcted normal mice, but not in infarcted transgenic mice. AT1 receptor expression was little changed in the groups, while AT2 receptor protein was increased in the transgenic groups. The Mas receptor expression was increased in infarcted normal mice, but not in the corresponding transgenic group.

Circulating HMGB1 levels increased in infarcted normal mice and infarcted ACE2 transgenic mice, albeit to a lesser degree. Tissue expression of HMGB1 increased in the hearts of normal infarcted mice, but not in infarcted ACE2 transgenic mice. Tissue staining for HMGB1 positive cells was performed to corroborate the findings. Similarly, the infiltration of inflammatory cells was reduced accordingly. Finally, ACE2 activation ameliorated hypoxia-induced cell death and upregulation of HMGB1 in cardiomyocytes. The protective effect was correlated with downregulation of HMGB1 and reduced downstream proinflammatory cascades.

The authors show convincingly that HMGB1 participates in the innate immune responses surrounding Ang II-induced target organ damage in the heart, a process known to involve NF-KB [11]. How ACE2 overexpression influences HMGB1 is unclear. Conceivably, the enzyme cleaves the protein. Another possibility involves the upregulated AT2 receptor in this model. More likely perhaps is an effect involving Ang1-7 and signaling through the Mas receptor. For instance, transactivation of ErbB family of receptor tyrosine kinases is inhibited by Ang1-7 via its Mas Receptor [12]. Mas, a G protein-coupled receptor, interacts with common heterotrimeric $\mathrm{G}$ proteins. Mas $\mathrm{C}$-terminal tail interacting proteins have been identified by mass spectrometry and proteomics [13]. A Mas "signalosome" has been proposed. D-Pro7-Ang-(1-7) is a specific Ang1-7 inhibitor. Agonists of the Mas receptor pathway are also being developed [14]. Further work using these tools will be necessary to elucidate the issue.

Respectfully, Friedrich C. Luft 


\section{References}

1. Bianchi ME, Agresti A (2005) HMG proteins: dynamic players in gene regulation and differentiation. Curr Opin Genet Dev 15:496506

2. Klune JR, Dhupar R, Cardinal J, Billiar TR, Tsung A (2008) HMGB1: endogenous danger signaling. Mol Med 14:476-484

3. Yang H, Hreggvidsdottir HS, Palmblad K, Wang H, Ochani M, Li J, Lu B, Chavan S, Rosas-Ballina M, Al-Abed Y et al (2010) A critical cysteine is required for HMGB1 binding to Toll-like receptor 4 and activation of macrophage cytokine release. Proc Natl Acad Sci U S A 107:11942-11947

4. Wang H, Bloom O, Zhang M, Vishnubhakat JM, Ombrellino M, Che J, Frazier A, Yang H, Ivanova S, Borovikova L et al (1999) HMG-1 as a late mediator of endotoxin lethality in mice. Science 285:248-251

5. Lotze MT, Tracey KJ (2005) High-mobility group box 1 protein (HMGB1): nuclear weapon in the immune arsenal. Nat Rev Immunol 5:331-342

6. Kikuchi K, Tancharoen S, Ito T, Morimoto-Yamashita Y, Miura N, Kawahara K, Maruyama I, Murai Y, Tanaka E (2013) Potential of the angiotensin receptor blockers (ARBs) telmisartan, irbesartan, and candesartan for inhibiting the HMGB1/RAGE axis in prevention and acute treatment of stroke. Int J Mol Sci 14:18899-18924

7. Nakamura T, Sato E, Fujiwara N, Kawagoe Y, Yamada S, Ueda Y, Koide H (2012) Changes in urinary albumin excretion, inflammatory and oxidative stress markers in ADPKD patients with hypertension. Am J Med Sci 343:46-51

8. Fournier D, Luft FC, Bader M, Ganten D, Andrade-Navarro MA (2012) Emergence and evolution of the renin-angiotensinaldosterone system. J Mol Med (Berl) 90:495-508

9. Gurley SB, Coffman TM (2008) Angiotensin-converting enzyme 2 gene targeting studies in mice: mixed messages. Exp Physiol 93: 538-542

10. Qi YF, Zhang J, Wang L, Shenoy V, Krause E, Oh SP, Pepine CJ, Katovich MJ, Raizada MK (2015) Angiotensin-converting enzyme 2 inhibits high-mobility group box 1 and attenuates cardiac dysfunction post-myocardial ischemia. J Mol Med (Berl). doi:10.1007/ s00109-015-1356-1

11. Mervaala E, Muller DN, Park JK, Dechend R, Schmidt F, Fiebeler A, Bieringer M, Breu V, Ganten D, Haller H et al (2000) Cyclosporin A protects against angiotensin II-induced end-organ damage in double transgenic rats harboring human renin and angiotensinogen genes. Hypertension 35:360-366

12. Akhtar S, Chandrasekhar B, Attur S, Dhaunsi GS, Yousif MH, Benter IF (2015) Transactivation of ErbB family of receptor tyrosine kinases is inhibited by Angiotensin-(1-7) via its Mas receptor. PLoS One 10:e141657

13. Tirupula KC, Zhang D, Osbourne A, Chatterjee A, Desnoyer R, Willard B, Karnik SS (2015) MAS C-terminal tail interacting proteins identified by mass spectrometry- based proteomic approach. PLoS One 10:e0140872

14. Oparil S, Schmieder RE (2015) New approaches in the treatment of hypertension. Circ Res 116:1074-1095 